
[0212-7199(2002) 19: 5; pp 234-236]
ANALES DE MEDICINA INTERNA
Copyright @ 2002 ARAN EDICIONES, S.L.

An. Med InTERnA (Madrid) Vol. 19, N. $^{\circ} 5$, pp. $234-236,2002$

\title{
Infección diseminada y severa por citomegalovirus en paciente inmunocompetente
}

\author{
S. IZQUIERDO RUBIO, C. TAXONERA SAMSÓ, J. M. LADERO QUESADA, \\ C. ALMANSA MENCHERO, M. DÍAZ-RUBIO
}

Servicio de Aparato Digestivo. Hospital Clínico San Carlos. Madrid

\author{
DISSEMINATED CYTOMEGALOVIRUS INFECTION IN IMMUNO - \\ COMPETENT PATIENTS
}

\begin{abstract}
RESUMEN
La infección por citomegalovirus en pacientes inmunocompetentes suele ser asintomática. Los pacientes inmunodeprimidos pueden presentar cuadros severos con mala respuesta al tratamiento. Presentamos el caso de un paciente alcohólico con infección diseminada por citomegalovirus con excelente respuesta al tratamiento con ganciclovir.
\end{abstract}

PALABRAS CLAVE: Infección. Citomegalovirus. Hepatitis. Neumonitis. Alcoholismo.

\begin{abstract}
Usually, cytomegalovirus infection dosen't cause symtons in immu nocompetents patients although sometimes can. In alcoholic and cirrho tic subjects can cause several and fatal infections. We describe a case of disseminated cytomegalovirus infection in an alcoholic patient with excellent response to ganciclovir.
\end{abstract}

KEY WORDS: Infection. Cytomegalovirus. Hepatitis. Pneumonitis. Alcoholic.

Izquierdo Rubio S, Taxonera Samsó C, Ladero Quesada JM, Almansa Menchero C, Díaz-Rubio M. Infección diseminada y severa por citome galovirus en paciente inmunocompetente. An Med Interna (Madrid) 2002; 19: 234-236.

\section{INTRODUCCIÓN}

La infección por CMV en personas inmunocompetentes suele pasar desapercibida pero en ocasiones puede causar síntomas por afectación de órganos diversos. Se han descrito casos de neumonitis, hepatitis, encefalitis, esofagitis y colitis por CMV en personas inmunocompetentes con buena respuesta al tratamiento con ganciclovir (1-7).

En pacientes inmunodeprimidos, la infección por CMV presenta una mayor severidad y en ocasiones mala respuesta terapéutica. Es frecuente la implicación del tracto gastrointes tinal, sobre todo colon seguido de estómago y esófago, con afectación en ocasiones a varios niveles. En los casos de infecciones severas puede producirse enfermedad diseminada con afectación de varios órganos a un mismo tiempo.

\section{CASO APORTADO}

Paciente de 49 años con etilismo crónico importante (> $200 \mathrm{~g}$ etanol /día), en los últimos días bebedor de 30 gr/día. Antecedentes de TBC pulmonar hace 3 años tratada y alergia a penicilinas.
Ingresa por primera vez por presentar en la última semana aumento del perímetro abdominal, dolor a nivel piso abdominal superior sin relación con la ingesta, ictericia cutáneomucosa, coluria con heces de coloración normal.

En la exploración destacaba $\mathrm{T}^{\mathrm{a}} 37.3^{\circ} \mathrm{C}$, intensa ictericia cutáneomucosa, leve desnutrición y abdomen distendido con ascitis moderada así como dolor a la palpación sobre todo a nivel epigástrico e hipocondrio derecho sin signos de irritación peritoneal y ruidos hidroaéreos normales junto a hepatomegalia de 3 traveses de dedo dolorosa.

En la analítica presentaba leucocitosis con neutrofilia, $\mathrm{T}^{\mathrm{o}}$ protrombina del $69 \%$, bilirrubina total $8 \mathrm{mg} / \mathrm{dl}$ (directa $5,1 \mathrm{mg} / \mathrm{dl}$ ), GOT 94 U/l, GPT 28 U/l, GGT 1533 U/l, FA 1300 U/l, Glucosa 59 mg/dl, alfafetoproteina $4,4 \mathrm{UI} / \mathrm{ml}$. En la ECO abdominal se objetiva hepatomegalia con hígado disecogénico con áreas hiperecogénicas compatibles con esteatosis, hipertensión portal con esplenomegalia, ascitis moderada, vesícula biliar, vía biliar y páncreas normales. Ante el cuadro febril se realizan Rx tórax y abdomen, hemocultivos y paracentesis diagnóstica sin encontrarse foco infeccioso. Serología virus hepatitis $\mathrm{A}, \mathrm{B}$ y $\mathrm{C}$ negativos.

El paciente mejora del dolor abdominal y fiebre, siendo dado de alta con los diagnósticos de hepatopatía crónica etílica con signos de hipertensión portal, descompensación hidrópica y probable hepatitis aguda alcohólica sin criterios de severidad (Índice de Maddrey de 28 ), por lo que no se indica tratamiento corticodeo.

Trabajo aceptado: 24 de noviembre de 2000

Correspondencia: Sonia Izquierdo Rubio. Servicio de Aparato Digestivo. Hospital Clínico San Carlos. C/ Martín Lagos s/n. 28040 Madrid 
Cuarenta días después acude por cuadro de malestar general, ictericia cutáneomucosa progresiva, coluria sin acolia, incremento del perímetro abdominal y edemas junto con disminución de la diuresis así como 4-8 dep./día blandas ocasionalmente negras y dolor abdominal tipo retortijón que cedía tras la deposición.

En la exploración además de la marcada ictericia cutáneomucosa y desnutrición severa se objetivó disminución del murmullo vesicular en ambas bases con crepitantes en base izquierda, ascitis moderada y dolor a la palpación profunda a nivel epigástrico así como edemas con fóvea hasta raíz del muslo. Tacto rectal normal.

En la analítica destaca leucocitosis con neutrofilia, glucosa 65 $\mathrm{mg} / \mathrm{dl}, \mathrm{T}^{\mathrm{o}}$ protrombina 50\%, GOT $69 \mathrm{U} / 1$, GPT33 U/l, GGT $271 \mathrm{U} / 1$, FA $669 \mathrm{U} / 1$, Bilirrubina $22 \mathrm{mg} / \mathrm{dl}$ (directa $17 \mathrm{mg} / \mathrm{dl}$ ), Creatinina 4.8 $\mathrm{mg} / \mathrm{dl}, \mathrm{K} 5,3 \mathrm{mmol} / \mathrm{l}$, Na $127 \mathrm{mmol} / \mathrm{l}$.

Durante el ingreso a pesar de mantener diuresis de unos 900cc presentó incremento de la creatinina hasta $7 \mathrm{mg} / \mathrm{dl}$ que se interpretó como posible insuficiencia renal aguda prerrenal en paciente en tratamiento diurético y cuadro diarreico asociado por lo que fue tratado inicialmente con expansión de volumen con escasa respuesta a la misma. Además se realizó una gastroscopia presentando esófago con varices grado II, gastropatía de hipertensión portal con erosiones que no sangraban así como una ulcera en cara anterior de antro pilórico aguda con coagulo adherido (Forrest IIb) que se esclerosó.

Ante la mala respuesta a la expansión de volumen y la persistencia de intensa leucocitosis y neutrofilia (19630 leucocitos con 86\% neutrófilos, $6 \%$ linfocitos, $5 \%$ monocitos) se planteó la posibilidad de la existencia de un cuadro séptico subyacente por lo que se comienza tratamiento antibiótico de amplio espectro, Imipenen, a dosis ajustadas a función renal.

En los días siguientes empeora la situación clínica, presentando intolerancia a la dieta con dispepsia pero sin disfagia, empeoramiento de las pruebas de función renal, la bilirrubina asciende a $28 \mathrm{mg} / \mathrm{dl}$ con directa de $17 \mathrm{mg} / \mathrm{dl}$ y presenta en la gasométrica: $\mathrm{pH} 7,3, \mathrm{pO}_{2} 54$ $\mathrm{mmHg}, \mathrm{pCO}_{2} 20 \mathrm{mmHg}, \mathrm{yCO}_{3} 10$.

Ante dicho agravamiento se decide la realización de nuevos estudios serológicos incluyendo CMV, Epstein Barr, toxoplasma, virus herpes, sífilis, nuevos hemocultivos y análisis del líquido ascítico así como nueva Rx tórax (la del ingreso fue normal). Presentando serología positiva Ig G e Ig M para citomegalovirus, siendo el resto de la misma negativa. En la $\mathrm{Rx}$ tórax se aprecia derrame pleural derecho y cisural con infiltrados intersticiales probablemente agudos en campos inferior y superior derecho así como cambios intersticiales en LSI. Dada la serología positiva para CMV se solicita antigenemia y cultivo para CMV que resultaron ser negativos e interconsulta a oftalmología no hallándose retinitis por CMV ni TBC.

Se inicia tratamiento con ganciclovir i.v. ajustadas a la función renal experimentando el paciente una mejoría espectacular, con un descenso de la leucocitosis, creatinina y bilirrubina, siendo a las $24 \mathrm{~h}$ de instaurado dicho tratamiento de 15.800 leucocitos $(74 \% \mathrm{~N})$, creatinina $3,2 \mathrm{mg} / \mathrm{dl}$, bilirrubina total $16,4 \mathrm{mg} / \mathrm{dl}$ (directa $10,6 \mathrm{mg} / \mathrm{dl}$ ) y a la semana, leucocitos $14.700(72,2 \% \mathrm{~N})$, creatinina $1,4 \mathrm{mg} / \mathrm{dl}$ y bilirrubina total $10,5 \mathrm{mg} / \mathrm{dl}$ (directa $6,8 \mathrm{mg} / \mathrm{dl}$ ), paralelamente se produce una evidente mejoría clínica con mayor tolerancia a la dieta, desaparición del cuadro diarreico y progresiva ganancia ponderal.

Al alta presentaba normalización de la leucocitosis, creatinina de $0,9 \mathrm{mg} / \mathrm{dl}$ y bilirrubina de 3,1 mg/dl, así como mejoría de los parámetros nutricionales (albúmina, colesterol, etc.). Se repite Rx tórax previa al alta con resolución completa de los infiltrados pulmonares agudos, persistiendo la lesión crónica a nivel LSI.

\section{DISCUSIÓN}

Se trata de un paciente con etilismo crónico activo importante y hepatopatía crónica con hipertensión portal y ascitis asociada. En el primer ingreso la existencia de leucocitosis y elevación de las cifras de bilirrubina eran sugerentes de probable hepatitis aguda alcohólica sobre hepatopatía crónica. El paciente no presentó en ningún momento encefalopatía. El Índice de Maddrey era de 28 (criterios de severidad Maddrey > 32) por lo que se decidió alta sin tratamiento corticoideo.

En el segundo ingreso el paciente además de una marcada leucocitosis y neutrofilia, ya presente en el primer ingreso, mostraba elevación importante de las cifras de creatinina y bilirrubina además de una hemorragia digestiva alta autolimitada por ulcus duodenal. Ante la sospecha de posible insuficiencia renal prerrenal y cuadro séptico asociado se trató con expansores de volumen y antibioterapia de amplio espectro sin respuesta.

Posteriormente, ante la presencia de serología IgM a CMV positiva y dado el mal estado del paciente, se decide, sin otras exploraciones, comenzar tratamiento con ganciclovir ajustado a la función renal. La respuesta fue excelente con mejoría tanto clínica (molestias gastrointestinales -dispepsia y diarrea-), analítica (función respiratoria y renal) así como radiológica con desaparición de los infiltrados intersticiales en la Rx tórax.

El diagnóstico de infección diseminada por CMV se basa en la existencia de neumonitis sin evidencia de otra causa, lesiones gástricas compatibles así como cuadro clínico (diarrea y dispepsia) compatible con afectación del tracto gastrointestinal por CMV. La rápida y completa respuesta clínica, bioquímica, gasométrica y radiológica al tratamiento con ganciclovir refuerza el diagnóstico.

La infección por CMV en sujetos inmunocompetentes suele ser asintomática aunque en ocasiones puede causar síntomas (neumonitis, esofagitis, encefalitis, etc.) con buena respuesta al tratamiento con ganciclovir (1-7). Los pacientes con cirrosis y alcoholismo poseen cierto grado de inmunodeficiencia celular pudiendo presentar cuadros severos por infección por CMV. En un estudio publicado por Varani y cols. se observó que la incidencia de infección aguda por CMV en pacientes cirróticos era superior a la que presentaba la población control (8). Además en una publicación reciente se presenta el caso de un paciente con hepatitis aguda alcohólica y cirrosis tratado con corticoides que falleció encontrándose en la autopsia del mismo una neumonía por CMV y $P$. carinii (9).

Por todo lo mencionado creemos que ante un paciente que presente un cuadro de fiebre, ictericia, leucocitosis y dolor abdominal sugerente de hepatitis aguda alcohólica debemos descartar la existencia de infección por CMV u otros gérmenes oportunistas antes de indicar tratamiento corticoideo,dado que este puede inducir cierto grado de inmunosupresión lo que favorecería la persistencia de la infección subyacente pudiendo producir cuadros de infección diseminada con un posible desenlace fatal. 


\section{Bibliografía}

1. Manian FA, Smith T. Ganciclovir for the treatment of cytomegalovirus pneumonia in an immunocompetent host. Clin Infect Dis 1993; 17: 137-8.

2. Serna-Higuera C, González-García M, Milicua JM, Muñoz V. Acute cholestatic hepatitis by cytomegalovirus in an immunocompetent patient resolved with ganciclovir: J Clin Gastroenterol 1999; 29: 276-7.

3. Pantoni L, Inzitari D, Colao MG, De Mayo E, Marini P, Mazzota F. Cytomegalovirus encephalitis in a non-immunocompromised patient: CSF diagnosis by in situ hybridization cells. Acta Neurol Scand 1991; 84: $56-8$.

4. Coll PP, Pacala JT, Hamilton CW. Cytomegalovirus colitis in an older woman, successfully treated with ganciclovir. J Fam Pract 1992; 34: 772-5.

5. López-Contreras J, Ris J, Domingo P, Puig M, Rabella N, Nolla J. Disse- minated cytomegalovirus infection in an immunocompetent adult successfully treated with ganciclovir. Scand J Infect Dis 1995; 27: 523-5.

6. Klauber E, Briski LE, Khatib R. Cytomegalovirus colitis in the immunocompetent host: an Overview. Scand J Infect Dis 1998; 30: 559-64.

7. Sakamoto I, Shirai T, Kamida T, Igarashi M, Koike J, Ito A, et al. Cytomegalovirus enterocolitis in an immunocompetent individual. J Clin Gastroenterol 2002; 34: 243-6.

8. Varani S, Lazzarotto T, Margotti M, Masi L, Gramantieri L, Bolondi L, et al. Laboratory signs of acute or recent cytomegalovirus infection are common in cirrhosis of the liver. J Med Virol 2000; 62: 25-8.

9. Ikawa H, Hayashi Y, Ohbayashi C, Tankawa H, Itoh H. Autopsy case of alcoholic hepatitis and cirrhosis treated with corticosteroids and affected by Pneumocystis carinii and cytomegalovirus pneumonia. Pathol Int 2001; 51: 629-32. 